\title{
Spectral and Angular Ground-Based Radar Backscatter Measurements of Greenland Snow Facies.
}

\author{
BAUMGARTNER ${ }^{1}$ F., JEZEK ${ }^{2}$ K., FORSTER ${ }^{3}$ R.R., GOGINENI ${ }^{4}$ S.P., and ZABEL ${ }^{5}$ I.H.H. \\ 1,2,3,5 The Byrd Polar Research Center, The Ohio State University, 1090 Carmack Road, \\ Columbus, OH-43210, USA. Tel: (614) 2921107, Fax: (614) 2924697. \\ ${ }^{3}$ Currently at the Department of Geography, 260 S. Central Campus Dr, \\ The University of Utah, Salt Lake City, UT 84112-92115. Tel: (801)581-3611, Fax: (810)581-8219. \\ ${ }^{4}$ Radar Systems and Remote Sensing Laboratory, The University of Kansas, 2291 Irving Hill Road, \\ Lawrence, KS-66045, USA. Tel: (785) 8647734, Fax: (785) 8647789. \\ ${ }^{5}$ Currently at M.I.T. Lincoln Laboratory, 244 Wood Street, \\ Lexington, MA-02420, USA. Tel: (781) 9812732, Fax: (781) 9812780. \\ Email: ${ }^{1}$ baum@iceberg.mps.ohio-state.edu, ${ }^{2}$ jezek@iceberg.mps.ohio-state.edu, ${ }^{3}$ forster@geog.utah.edu, \\ ${ }^{4}$ gogineni@rsl.ukans.edu, and ${ }^{5}$ zabel@1l.mit.edu
}

\begin{abstract}
Snow facies, or melt zones, on the Greenland Ice Sheet are correlated with brightness patterns on spaceborne radar imagery [1] and [2]. To better relate radar scattering signatures to individual zones, we investigate the relationship between radar scattering and firn physical properties. We operated surface-based radar systems at five different sites on the Greenland Ice Sheet. In the dry snow zone the angular variation of the backscattering coefficient indicates that at high incidence angles the return energy is dominated by volume scattering. We also observe a systematically higher backscattering coefficient when the physical temperature is low and all the other parameters are identical. In the wet snow zone the backscatter coefficient is temporally dependant as the temperature variations affect the moisture content and modifies the spectral backscattered energy. The snow and ice surface roughnesses determine the angular response. In the percolation zone, the backscatter coefficient is independent of the frequency and the angular response is also controlled by the ice structures (surface roughness, lenses, and pipes).
\end{abstract}

\section{INTRODUCTION}

We conducted in-situ measurements on the Greenland Ice Sheet to investigate relationships between radar scattering mechanisms and firn physical properties. We collected data between September 1992 and May 1995 at five different sites which span Greenland's snow facies [3] and [4]. The five sites were GITS $(77.10 \mathrm{~N} 61.00 \mathrm{~W})$ representing the dry sow zone, NASA-U(73.00N 50.50W) in the transition between the dry snow and the percolation zone (but no percolation features were observed in 1995 above a depth of 7-8 meters), Crawford Point(70.00N 47.00W) and Dye-2(66.5N 46.3W) in the percolation zone, and Swiss Camp $(69.57 \mathrm{~N} 49.30 \mathrm{~W})$ in the wet snow zone.

An ultra-wide band (uwb) radar system and a $13.5 \mathrm{GHz}$, frequency modulated continuous wave (fmcw) radar system were used to collect data. The uwb radar operated from 500 $\mathrm{MHz}$ to $18 \mathrm{GHz}$ in $11 \mathrm{MHz}$ steps. The fmcw radar operated with a $1.6 \mathrm{GHz}$ bandwidth. Both systems were used to measure angular backscattering responses from 0 to 50 degrees. Backscatter coefficients measured at $\mathrm{C}, \mathrm{X}$, and $\mathrm{Ku}$ band $(13.5$ and $17 \mathrm{GHz})$ for the uwb system are presented.

The uwb radar system probed to a maximum depth of about 10 meters. The $3 \mathrm{~dB}$ antenna beamwidth is quite large (60 and 10 degrees at 2 and $18 \mathrm{GHz}$ respectively). Therefore, we applied a correction to the illuminated area $A_{\text {ill }}$ for each frequency down to the smallest angle of incidence where the correction was possible. This allowed us to derive a calibrated unitless equivalent surface backscatter coefficient

$$
\sigma^{0}=\frac{\left(\sum P_{i}\right) R_{s}^{4}}{P_{l} R_{l}^{4} A_{i l l}} \sigma_{l}
$$

where a Luneburg lens was used for calibration. The radar cross section of the lens $\sigma_{l}$ is expressed in meters squared. The sum is made over the successive power returns $P_{i}$ from the snow, and $R_{s}$ is the range from the radar to the snow surface. $P_{l}$ is the measured return power of the lens and $R_{l}$ is the range from the radar to the lens.

\section{DRY SNOW ZONE}

In this section we present the results obtained at GITS and NASA-U. Based on core data available at the two sites and on the maximum probing depth of our radar system, no melt features were observed at the two sites. Snow pit data (150 $\mathrm{cm}$ deep) revealed similar physical properties at the two sites. Near surface temperatures were different at the two sites. Profiles of snow temperature show differences up to 7 degrees Celsius within the first 0.5 meter between GITS and NASA-U.

Fig.1 shows the equivalent surface backscattering coefficient measured at GITS by the uwb system and at C, X, and $\mathrm{Ku}$-band. Because the radar has a fixed number of range gates and operated from a constant height, the sampling depth 
into the snow drops from 10 meters at normal incidence to about 4 meters at 50 degrees.

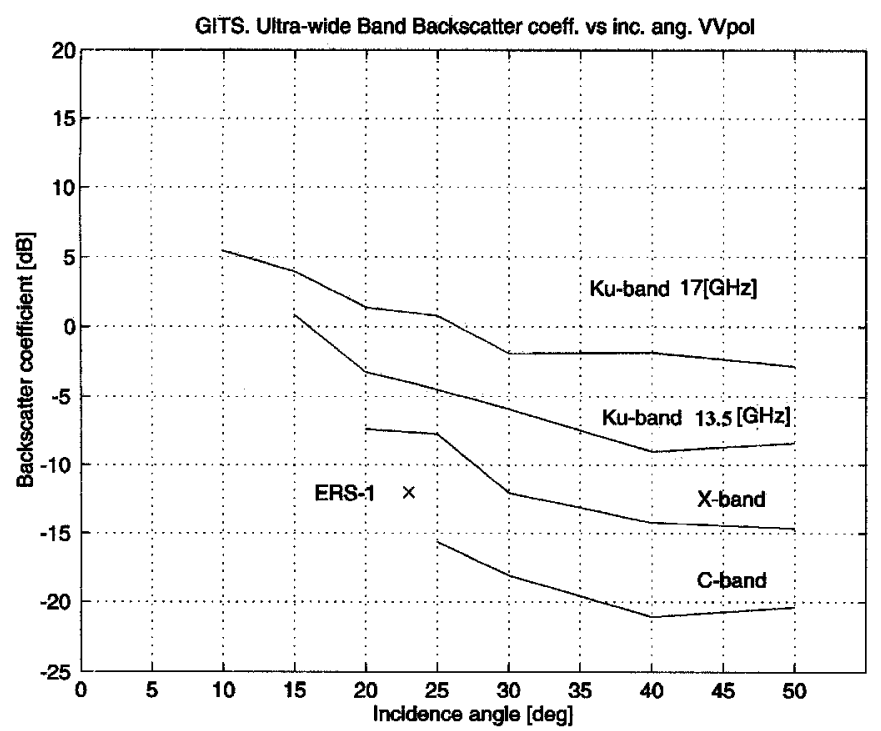

Figure 1.

Fig. 1 indicates that at high incidence angles the backscatter coefficient is independent of the incidence angle. This is suggestive of volumetric scattering. We have not applied a wide beam correction to our low incidence angle data. Consequently the values may be artificially high for incidence angles less than 25 degrees. Nevertheless, there is a suggestion that the backscattering energy deviates from a pure volumetric backscattering mechanism.

Also shown is the average ERS-1 backscatter coefficient measured during the same period of 1995 at GITS. The ERS1 value represents an average of about 500 pixels, each having a resolution of 25 meters, whereas the uwb value corresponds to an average of three spots, each illuminating an area of about a meter squared or less. We attribute the difference in backscatter coefficients to our imaging geometry and approximations made in the derivation of (1). Essentially, we have assumed a constant range to the surface where in fact we need to apply a variable range correction for the volume [5]. We believe this accounts for a 2-3dB underestimate in the backscatter coefficient.

Fig.2 shows the different responses of the uwb radar system, the response of the fmcw radar system, and the backscatter coefficient value of the ERS-1 at NASA-U. Excellent agreement is observed by comparing the results of the fmcw radar system and the $\mathrm{Ku}$-band response of the uwb system. The response for incidence angles below 20 degrees is dominated by the wide antenna beam effects. We note systernatically higher backscatter coefficients values at NASA-U than at GITS for both the uwb system and the ERS1 values. We attribute this difference to a lower physical snow temperature observed at NASA-U $\left(-21^{\circ} \mathrm{C}\right)$ than at GITS $\left(-16^{\circ} \mathrm{C}\right)$. The effect of temperature is verified by running a volumetric backscattering model that includes the physical temperature as a parameter. We find that firn having a physical temperature value of $-20^{\circ} \mathrm{C}$ is a stronger scatterer than firn with a physical temperature of $-13^{\circ} \mathrm{C}$ by about $2 \mathrm{~dB}$. The temperature effect on the backscatter energy can also be observed by inspecting the snow returns of the first 0.1 meter at GITS and NASA-U for the highest incidence angles where the volumetric mechanism dominates the scattering process. At this depth the firn physical properties are nearly identical. The temperature at GITS was $-14^{\circ} \mathrm{C}$ and $-20^{\circ} \mathrm{C}$ at NASA-U. We measured a $3 \mathrm{~dB}$ difference between the sites at an incidence angle of 50 degrees. We found a $2 \mathrm{~dB}$ difference at $13.5 \mathrm{GHz}$.

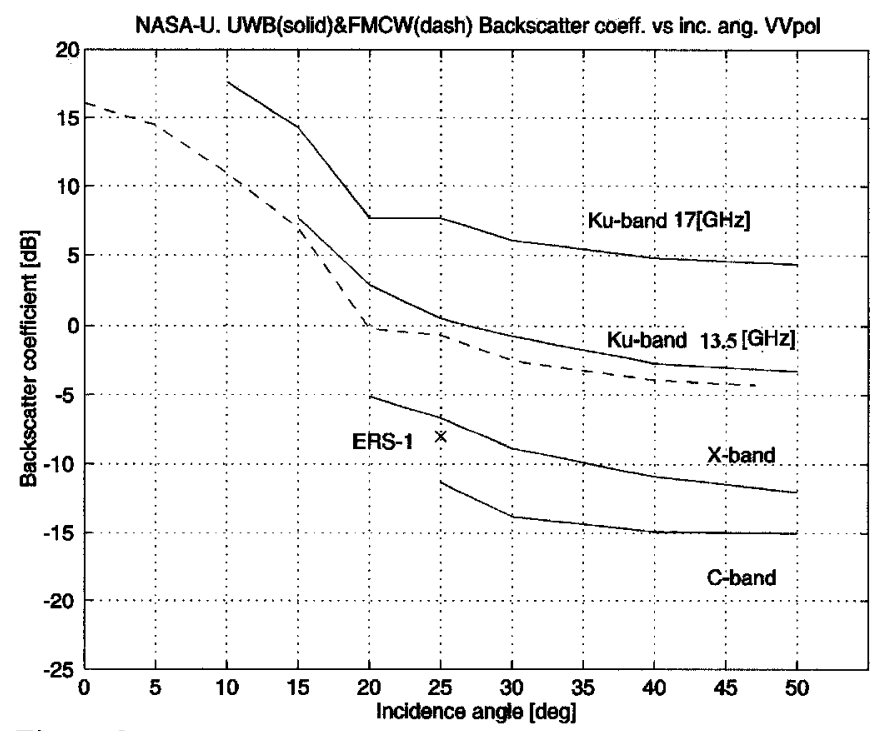

Figure 2.

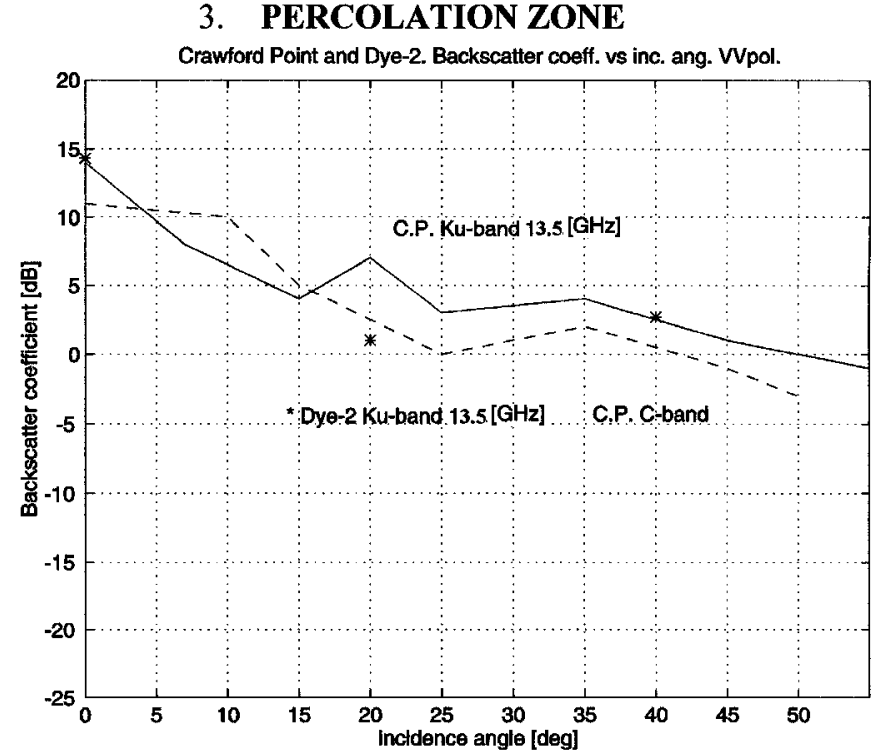

Figure 3

At Crawford Point and at Dye-2, firn metamorphosis is dominated by seasonal melt, which leads to marked contrast in the vertical structure of the winter and summer firn.

Fig. 3 shows the backscatter coefficient versus incidence angles at $\mathrm{Ku}$-band (Crawford Point and Dye-2) and C-band 
(Crawford Point). At both sites, the scattering from the ice features are much stronger than that from the volume distribution of winter snow grains above it. Those large scatterers represented by ice lenses, pipes, and layers lead to a backscatter response that is independent of the frequency and of the higher incidence angles ( 25 to 50 degrees).

\section{WET SNOW ZONE}

Here we present the backscattering coefficients measured at Swiss Camp by the uwb radar system on two consecutive days. The snow properties were identical during the two days, and the depth to the Aufeis was about 0.65 meter.

Fig.4 illustrates the spectral and angular responses of the backscattered energy. First we note an incidence angle independent response of the backscatter coefficients at all frequencies. This is attributed to the very rough surface of the ice layer at this spot as observed by the pit data. The spectral responses indicate a higher backscatter coefficient value as the frequency increases. The roughness of the ice layer probably determines the spectral responses and less energy is backscattered at $\mathrm{C}$-band than at $\mathrm{Ku}$-band.

We speculate that the difference between the data of the $17^{\text {th }}$ and the $18^{\text {th }}$ is due to the fact that the measurements were not made at the exact same location. This might result in an absolute level change as the roughness of the ice layer could be spatially variable.

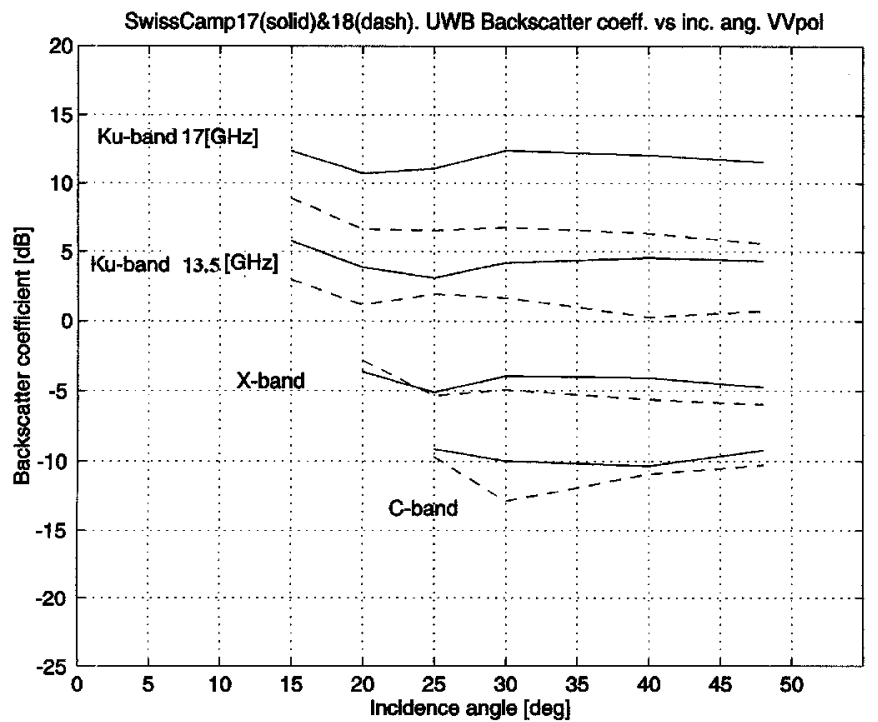

Figure 4.

\section{CONCLUSIONS}

Inspection of the spectral and angular responses of the backscatter energy at different sites (snow facies) over the Greenland Ice Sheet indicate that

1) In the dry snow zone, the backscatter coefficient is sensitive to the near surface temperature. Typical spectral and angular responses of the dry snow zone are illustrated in fig.5.
2) In the percolation zone, the backscatter coefficient is totally dominated by the ice structures (lenses, pipes, and layers), and the spectral and angular responses can be represented by a constant value for incidence angles above 20 degrees (fig.3).

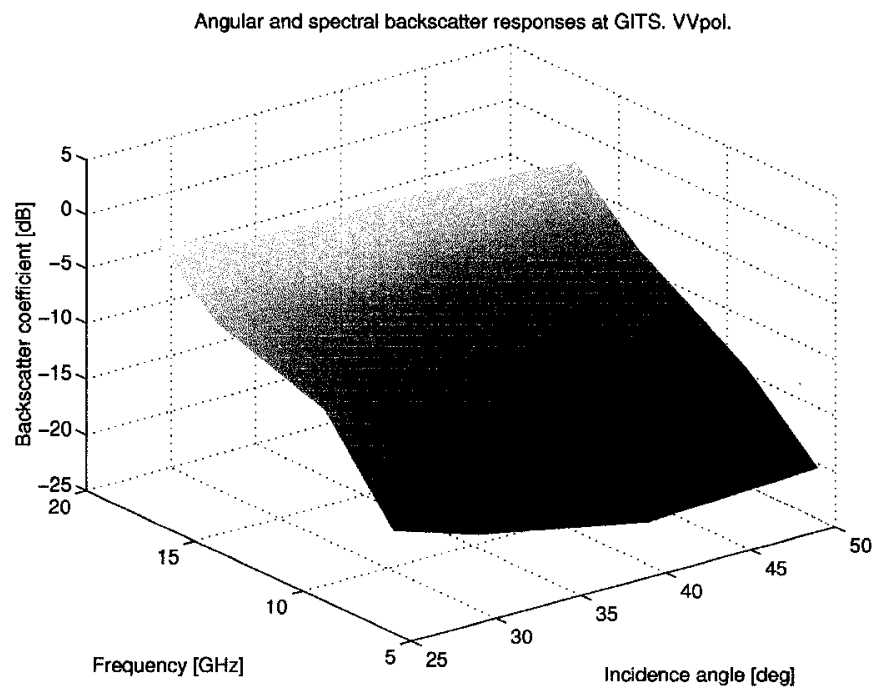

Figure 5.

3) In the wet snow zone, the presence of the thick ice layer leads to different spectral responses and a higher backscatter value is observed at higher frequencies (fig.4).

Based on the above remarks, we conclude that a better snow facies delineation between the percolation zone and the wet snow zone is obtained during the winter season by using $\mathrm{C}$-band data rather $\mathrm{Ku}$-band data. Also, the different absolute levels of the backscatter coefficient values at $\mathrm{C}$-band for the different snow facies (the lowest in the dry snow zone and the highest in the percolation zone) permit us to characterize the snow facies type under study.

\section{REFERENCES}

[1] M. Fahnestock, R. Bindschadler, R. Kwok, and K. Jezek, 1993, Greenland Ice Sheet Surface Properties and Ice Dynamics from ERS-1 SAR imagery, Sciences, 262, pp.1530-1534.

[2] D. Long and M. Drinkwater, 1994, Greenland ice-sheet surface properties observed by the Seasat-A scatterometer at enhanced resolution, J. of Glaciology, vol. 40, No. 135, pp. 213-229.

[3] K. Jezek, P. Gogineni, and M. Shanableh, 1994, Radar Measurements of Melt Zones on the Greenland Ice Sheet, Geophysical Research Letters, vol. 21, No. 1, pp. 33-36.

[4] I. Zabel, K. Jezek, P. Baggeroer, and P. Gogineni, 1995, Ground-based radar observations of snow stratigraphy and melt processes in the percolation facies of the Greenland Ice Sheet, Annals of Glaciology, 21, pp.40-44.

[5] H. Rott, K. Sturm, and H. Miller, 1993, Active and passive microwave signatures of Antarctic firn by means of field measurements and satellite data, Annals of Glaciology, vol. 17, pp. 337-343. 